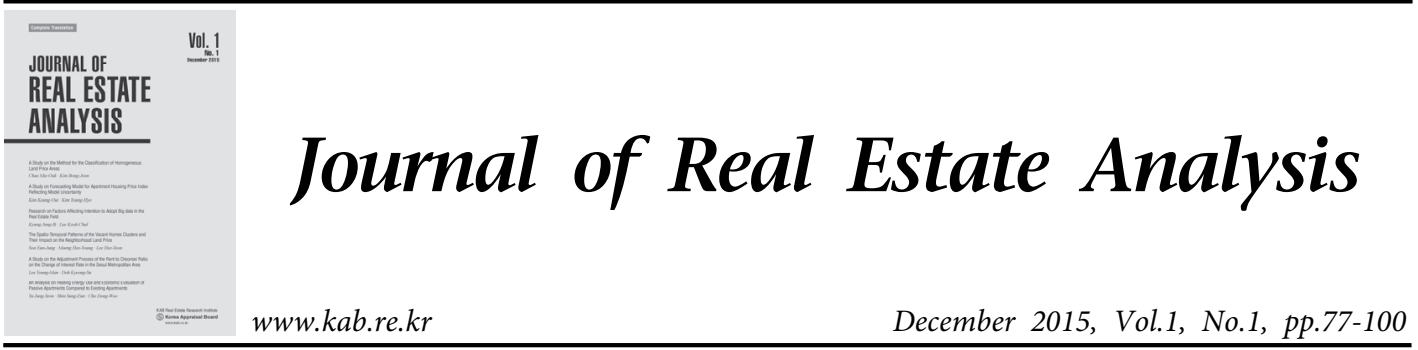

\title{
The Spatio-Temporal Patterns of the Vacant Homes Clusters and Their Impact on the Neighborhood Land Price* - The Case of Busan Metropolitan City -
}

\author{
Son Eun-Jung ${ }^{* *}$, Maeng Hee-Young ${ }^{* * *}$ and Lee Hee-Yeon ${ }^{* * * *}$
}

\begin{abstract}
| Abstract |
It is acknowledged that abandoned properties have negative social and environmental impacts on the adjacent neighborhood, depressing its land value. This study aims to investigate both spatio-temporal patterns and characteristics of the clusters of vacant homes and to analyze their impact on the neighborhood land price. As for the spatio-temporal patterns in Busan Metropolitan city, the main cluster has been continually fixed in downtown for the past 10 years and the cluster areas have been gradually expanded to their surrounding districts. The socially disadvantaged who have lived in these clusters reside in inferior and deteriorated housing facilities with physically poor and unsafe surrounding environment. As for the impact on the neighborhood land price, it is shown that the spatio-temporal patterns of the vacant homes clusters and those of the districts with low prices of residential land are quite similar. This study may give some significant insights into establishing efficient policies such as urban regeneration and residential environment improvement projects of local authorities which have suffered from the increment of vacant homes in the city of Busan.
\end{abstract}

Key Words: Vacant homes clusters; Spatio-temporal pattern; Neighborhood land price; Hotspot analysis

* This article is based on the study, which was primarily in the [Journal of Real Estate Analysis, Vol.1, No.1, pp.71 90, (in Korean)].

This research was conducted in 2015 with the support of 2015 Convergence Research Task Support Project (No.940-20150005) funded by the Seoul National University R\&DB Foundation.

** Doctoral course at Dep. of Environmental Planning, Graduate School of Environmental Studies, Seoul National University (Lead author, bedel337@snu.ac.kr)

*** Master's course at Dep. of Environmental Planning, Graduate School of Environmental Studies, Seoul National University (maenghy91@snu.ac.kr)

**** Professor at Dep. of Environmental Planning, Graduate School of Environmental Studies, Seoul National University (Corresponding author, leehyn@snu.ac.kr) 


\section{Introduction}

Owing to rapid urbanization since the 1960s, South Korea experienced the problems of shortage in urban land, housing, and infrastructure, and the expansion of built-up areas has been rapidly carried out. Recently, however, she has seen the rapid progress of low fertility and population ageing, which have resulted in serious problems. Particularly, the decrement in population in most regions has led to a rapid increase in various types of abandoned properties such as vacant homes, vacant stores, closed schools, and abandoned industrial properties, as well as a sharp decline in demand for land and buildings. The phenomenon of unused properties in the existing urban areas will be accelerated, for it is forecast that the tendency of depopulation will continue in the future, as well; and it is expected that the problem of managing and using abandoned properties will emerge as a very urgent issue.

The occurrence of vacant homes in deteriorated residential areas and ensuing problems have already been observed in local small and medium-sized cities, rural areas, and some large cities. The seriousness of the problem is great because it becomes more likely that abandoned properties will occur collectively at the same time over extensive spaces within a short time, if the tendency of depopulation continues. Among diverse types of abandoned properties, the increase in vacant homes looms large, for relevant local residents experience it directly within their own districts. A considerable number of studies have shown various negative effects arising from the improper management and neglect of vacant homes, such as a fall in the value of properties, the deterioration of physical and mental health, the reduction of vitality in community, an increase in environmental pollution due to illegal dumping, an increase in crimes, an increase in fire, the disfiguration of urban scape, stigmatization as economically and socially underdeveloped district (Accordino and Johnson, 2000; Branas et al., 2011; Cohen et al., 2003; Heckert and Mennis, 2012; Schilling, 2002; Schilling and Logan, 2008).

Just as the urban growth process needs urban planning, so does the urban shrinking process in which population decreases. The greatest change seen in Germany and the United States, where shrinking cities are under active discussion, is a paradigm shift from growth-centered planning to shrinkage-accepting planning. That is, the concept of urban decline, which was used as a negative concept under urban growth paradigms, is being converted into more positive concepts; and diverse policies are being implemented with a changed perception that re- 
gards urban crisis as an opportunity (Kabisch et al., 2006; Oswalt, 2006; Pallagst, 2009; Reckien and Martinez-Fernandez, 2011; Wiechmann and Pallagst, 2012). These policies regard vacant homes as potential assets rather than nuisances, and focus on managing or actively utilizing vacant homes or vacant land so that they may have positive effects on relevant districts.

Recently, methods for utilizing vacant homes are under discussion in Korea as well (Kim Youn-jin, 2009; An Hyun-jin and Park Hyeon-young, 2013; Woo Joo-hee et al., 2009; Lee Ji-sun and Sung Hyun-gun, 2010; Lee Chang and Lee Jae-woo, 2015; Lee Chun-hi, 2011; Lee Hwa-ryong et al., 2012; Lim Yoo-kyoung and Lim Hyun-sung, 2012; Choi Jae-pil et al., 2010; Ha Chang-ho et al., 2013). Most domestic studies, however, remain at the level of suggesting methods for fragmentary or partial utilization limited to specific vacant land (vacant homes, abandoned rail yards, abolished school buildings, relocated sites) or suggesting a single use (cultural use, space for sport-for-all facilities or community, housing support to the socially disadvantaged, vegetable garden) on vacant land having various characters. In addition, they have only investigated vacant homes that already occurred, and very few studies have investigated when and how vacant homes are generated, or the patterns of their distribution over time.

Against the background of the above, this study aimed to identify the spatio-temporal patterns of vacant home clusters in Busan and to analyze their impact on neighborhood land price. The formation of slums in the inner city and deprived community has been so much accelerated in Busan that top 40\% of nationwide deprived dongs are concentrated in Busan.

Deteriorated house clusters and vacant homes in the original downtown of Busan continue to increase as inner city decline has been accelerated due to the relocation of industrial enterprises, including footwear enterprises, to other regions since the 1990s, low fertility \& ageing, and new town development. To solve the problem of vacant homes, the Busan City Government is carrying out a complete enumeration survey, and is trying to work out methods for managing vacant homes systematically, such as the institution of a municipal ordinance for empty house maintenance support.

The detailed objectives of this study are as follows: First, it intends to analyze how vacant home clusters are spatially distributed in Busan, and how the spatial distribution changes over time. Second, in order to identify the characteristics of the vacant home clusters, it intends to analyze the socio-demographic characteristics of residents in the 
clusters, the characteristics of housing environment, and the characteristics of neighborhood residential environment. Third, it intends to analyze the impact of the vacant home clusters on price. That is, it will find the correlation between the land price of the vacant home clusters and that of neighborhood residential properties by overlaying the distribution map of average residential parcel prices with the distribution map of vacant home clusters for overall dongs in Busan. Through the above investigation, this study intends to provide information required to establish diverse policies including urban regeneration and residential environment improvement projects for vacant home clusters.

\section{Review of Previous Studies}

In domestic studies, the following terms were used in relation to vacant land including vacant homes: idle space (under-used space, unused or misused space, vacant space), idle land, vacant plot, idle facilities, empty home (vacant house, abandoned house), vacant homes, abandoned and unfinished buildings, vacant store, facility relocated site, disused industrial site, abandoned rail yards, and abolished school buildings; and in the case of overseas studies, the terms of vacant land, vacant lots, vacant property, abandoned property, and so on are used.

Domestic studies on methods for the utilization of vacant land mainly focus on utilizing various idle space for specific uses (cultural utilization) (Kwak Soo-jung, 2006; Kim Youn-jin, 2009; Woo Joo-hee et al., 2009), or utilizing specific idle space (vacant homes, abandoned rail yards, abolished school buildings, abandoned and unfinished buildings, and so on) for the creation of sport-for-all facilities or community space, housing support to the socially disadvantaged, the creation of vegetable gardens, and so on (Yu Kwang-heum and Lim Yoo-kyoung, 2013; Lee Ji-sun and Sung hyun-gun, 2010; Lee Chun-hi, 2011; Lee Hwa-ryong et al., 2012; Choi Jae-pil et al., 2010; Ha Chang-ho et al., 2013). Most of them end in presenting the survey of idle space status and suggesting fragmentary solutions in a particular area; and some conducted legal and institutional reviews for the utilization of idle space (Lee Hwa-ryong et al., 2012; Lim Yookyoung and Lim Hyun-sung, 2012; Yu Kwang-heum and Lim Yoo-kyoung, 2013). A relatively small number of studies focused on vacant homes; some simply identify the status of vacant home distribution in a specific city (Lee Dong-gi et al., 2005; Yim Jeong-ah et al., 2008), suggest methods for the utilization of vacant homes at the level 
of urban and residential regeneration (Lee Jun-hyung and Shin Joong-jin, 2014; Ha Chang-ho et al., 2013), or suggest improvements to empty homes or introduce overseas institutions and cases (Kim Hong-gi, 2013; An Hyun-jin and Park Hyeon-young, 2013; Lee Jae-woo, 2013).

On the other hand, in overseas countries, studies on vacant land were actively carried out in the United States and Germany, where a large amount of vacant land occurs in industrial cities, which grew in the period of Fordism, due to a rapid decrease in population combined with economic depression arising from the change of industrial structure (Pagano and Bowman, 2000). Mostly, they investigate policies on the utilization of vacant land under a new paradigm that perceives vacant land as resources, and some recent studies evaluated the potential of vacant land, and carried out empirical analysis on the effects of vacant land utilization. Particularly, studies have been very actively carried out to empirically analyze economic effects, which can be obtained by managing vacant land through the greening of vacant land, using methodologies such as hedonic models, difference in differences, geographical weighted regression (GWR), and so on (Heckert and Mennis, 2012; Heckert, 2013; Kaufman and Cloutier, 2006). Further, the social or ecological effects of vacant land were analyzed in terms of sustainability, or neighborhood effects were analyzed by linking the social effects of vacant land utilization to the safety, health, etc. of community (Branas et al., 2011; Garvin et al., 2013; Krusky et al., 2015; Mcphearson, et al., 2013). In addition, some studies analyzed the level of ecosystem services provided by vacant land, with the perception that vacant land is part of urban ecosystem (Burkholdr, 2012; Robinson and Lundholm, 2012). Kremer, et al. (2013) investigated actual vacant lot uses, and analyzed their relationships with neighborhood income, neighborhood population density, green density in neighborhood, distance to green, and green density within vacant lots. Their findings suggest the possibility that in the case of low-income high-density neighborhood districts, vacant land, which is potential resources still remaining unused, could be important ecological resources. Like this, in the case of overseas countries, empirical analyses on vacant land utilization and its utilization effects have been conducted from very various aspects, compared with Korea.

As for studies in Korea, however, there are meager studies on where vacant home clusters are distributed, or whether the clusters are gradually fixed in a particular district, are increasingly expanded into surrounding areas, or are reduced over time. In 
particular, there is no study that has analyzed in which housing environment or neighborhood environment the socially disadvantaged in the clusters reside, or changes in the realestate price of neighborhood near vacant home clusters.

\section{The Spatio-temporal Patterns of Vacant Home Clusters and the Characteristics of the Clusters}

\section{Research Method and Data}

1) Research method

This study intends to analyze the spatio-temporal patterns of vacant home clusters at 201 administrative dongs 1 ) of Busan in the years of 2005, 2010, and 2015; and to analyze the socio-demographic characteristics of residents in the vacant home clusters, the characteristics of their housing environment, and the characteristics of neighborhood residential environment. What is most important in analyzing the spatio-temporal patterns of vacant home clusters is the method of vacant home cluster selection. To select vacant home clusters, this study was carried out in four stages.

(Stage 1) Calculating the ratios of vacant homes by administrative dong for 2005, 2010, and 2015

(Stage 2) Selecting a district with $G_{i}^{*} \geq 2.58$ at three points of time by ArcGIS Hot Spot Analysis

(Stage 3) Analyzing the spatio-temporal patterns of vacant home clusters, using the overlay function of ArcGIS

(Stage 4) Analyzing the characteristics of residents, housing environment, and neighborhood residential environment in the selected vacant home clusters

First, Hot Spot Analysis, one of cluster analysis methods in ArcGIS, was carried out to select vacant home clusters. The Hot Spot Analysis is a method for showing the degree of object clustering, and the calculated Getis-Ord $G_{i}^{*}$ statistic is a $\mathrm{Z}$ score. If the $G_{i}^{*}$ value of a relevant district and its neighboring districts shows a large positive value ( $\mathrm{Z}$ score $\geq 1.96$ ) and the districts form a

1) Administrative dongs as of January 1, 2015 was the reference for analysis; provided that for the ease of analysis, some administrative dongs that had been divided into several dongs were regarded as one dong in this study (for example, Jwa 1-dong, Jwa 2-dong, Jwa 3-dong, and Jwa 4-dong in Haeundae-gu were unified into Jwa-dong), for this study used data of the three years. 


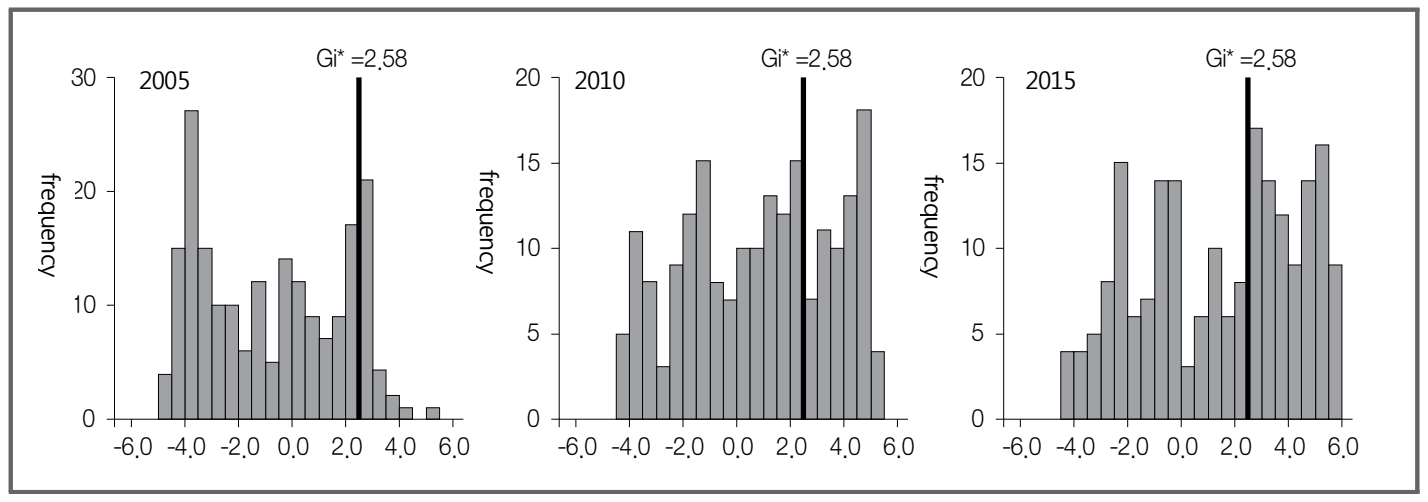

Fig. 1. $G_{i}^{*}$ statistic distributions and distributions with $G_{i}^{*} \geq 2.58$ by dong in Busan

cluster, the relevant district is extracted as a hot spot. On the contrary, if the $G_{i}^{*}$ value of a relevant district and its neighboring districts shows a small negative value ( $\mathrm{Z}$ score $\leq-1.96)$, and the districts form a cluster, the relevant district is extracted as a cold spot (Lee Hee-yeon et al., 2015). An equation for calculating the Getis-Ord $G_{i}^{*}$ static is as shown in Eq. (1) below.

$$
G_{i}^{*}=\frac{\sum_{j=1}^{n} w_{i, j} x_{j}-\bar{X} \sum_{j=1}^{n} w_{i, j}}{S \sqrt{\frac{\left[n \sum_{j=1}^{n} w_{i, j}^{2}-\left(\sum_{j=1}^{n} w_{i, j}\right)^{2}\right]}{n-1}}}
$$

$x_{j}$ : the attribute value for region $j$

$w_{i, j}$ : the spatial weight between $i$ and $j$

$n:$ the total number of regions

$$
\bar{X}=\frac{\sum_{j=1}^{n} x_{j}}{n}, \quad S=\sqrt{\frac{\sum_{j=1}^{n} x_{j}^{2}}{n}-(\bar{X})^{2}}
$$

First, hot spot dongs were extracted, with $G_{i}^{*} \geq 1.96$ as the reference. As a result, among a total of 201 dongs, 43 hot spot dongs (approximately 21\%) were extracted in 2005, 82 (approximately 41\%) in 2010, and 97 (approximately 48\%) in 2015, respectively. Fig. 1 shows histograms for the distributions of $G_{i}^{*}$ statistics in 2005, 2010, and 2015 calculated for the dongs. If the dongs are extracted with $G_{i}^{*} \geq 1.96$ as the reference, too many dongs are extracted, which makes it rather difficult to identify the distribution characteristics of vacant home clusters. Therefore, this study extracted clusters after raising the reference to $G_{i}^{*} \geq 2.58$. As a result, 23 hot spot dongs (approximately $11 \%$ ) were extracted in 2005, 61 (approximately $30 \%$ ) in 2010, and 86 (approximately 43\%) in 2015, respectively; and thus the relatively clear spatial distributions of vacant home clusters appeared. To identify whether the 
vacant home cluster distribution of the extracted dongs is fixed in particular space, or is expanded into surrounding areas or is reduced during the period from 2005 to 2015, this study used the overlay function of ArcGIS. Further, among the extracted dongs, 19 vacant-home-cluster dongs (top 10\%), which were extracted at all the three points of time, were selected to analyze the socio-demographic characteristics of their residents, and the characteristics of their housing environment and neighborhood residential environment.

\section{2) Data}

Data used to extract the vacant home clusters were data on empty house ${ }^{2)}$ in the 2005 Population and Housing Census and the 2010 Population and Housing Census conducted by Statistics Korea, and data of 2015 Busan Vacant Homes Status Survey. The vacant homes in this study are limited to build- ings that have been neglected for a long time without being used or in a dilapidated condition. On the assumption that an empty house will be usually found among detached housing rather than collective housing, this study selected detached houses that were vacant for one year or longer, and calculated the ratio of vacant homes at dong for 2005 and 2010 by dividing the number of vacant detached houses at dong by the number of detached houses at the same dong in the relevant year. The 2015 Population and Housing Census has not been conducted yet, and thus for the year of 2015, the ratio of vacant homes at dong was calculated by using data of the Vacant Homes Status Survey, which has been conducted annually since 2013 by Busan Metropolitan City. Consequently, there are limitations on direct comparison between the ratios of vacant homes at dong for 2010 and 2015.3)

In addition, the microdata of the 2010

2) The 'empty house' in the Population and Housing Census refers to detached housing, apartment, row housing, multi-household housing, or housing within non-residential building, where no one lives during a survey period on the grounds of sales, lease, move, etc. The Population and Housing Census Statistics provides data on empty houses according to housing types (detached housing, apartment, row housing, multi-household housing, and housing within non-residential building); and provides information on the reason for being vacant (sales, lease, move, unsold apartment, non-moving in, under repair, temporary (infrequent) use, for business use, etc.), the period of being vacant (below 3 months, 3-6 months, 6-12 months, above 12 months), and the degree of damage (no damage, partially damaged).

3) Data on empty houses are the Population and Housing Census for 2005 and 2010, and the Vacant Home Status Survey conducted by Busan city for 2015. The Population and Housing Census is a sampling survey and the Busan Survey is a complete enumeration survey. Thus, data on empty houses may vary due to differences in methods between the sampling survey and the complete enumeration survey. Actually, the total number 
Population and Housing Census, statistics yearbooks published by Gus in Busan city, and the data of the 2014 Busan ElderlyLiving-Alone Status were used to analyze the socio-demographic characteristics of residents in the vacant home clusters, characteristics of their housing environment, and the physical characteristics of neighborhood. Particular emphasis was laid on identifying how much inferior the housing environment of the socially disadvantaged who lived in the vacant home clusters was and how much physically poor and unsafe their surrounding environment was. Further, the characteristics of various projects carried out for the vacant home clusters by local governments were also investigated.

\section{Analysis of the Spatio-temporal Patterns of the Vacant Home Clusters}

Prior to extracting the vacant home clusters, the Busan vacant-home ratio choropleth map by dong, using the data of the 2010 Population and Housing Census, and the 2015 vacant-home dot map by dong were created. In the case of 2010, since only vacant home data collected according to dongs were available, the choropleth map was created to visualize the spatial distribution of dongs of high vacant home ratios. In the case of 2015, however, the actual locations of vacant homes were identified by geocoding the addresses of vacant homes and mapping the occurrence spots of vacant homes. As for dongs of the high numbers or ratios of vacant homes, Beomil 5-dong in Dong-gu, Gamcheon 2-dong in Saha-gu, Yongho 2-dong and Uamdong in Nam-gu, Nambumin 2-dong in Seo-gu, and Cheonghak 2-dong and Yeongseon 2-dong in Yeongdo-gu belong to them, as shown in Fig. 2.

On the other hand, dongs with $G_{i}^{*} \geq 2.58$ were extracted for each time point of 2015, 2010, and 2015, using the Hot Spot Analysis, and then comparison was made to identify how the spatial distribution of vacant home clusters in Busan changed between 2005 and 2015. As a result, it was found that the vacant home clusters were concentrated in the original downtown (Jung-gu, Dong-gu, Seo-gu, and Yeongdogu), and expanded to surrounding districts over time (See Fig. 3). In 2005, 23 dongs (approximately 11\%) including some dongs in Saha-gu and Gangseo-gu were extracted,

(ratio) of empty houses in Busan shows 3,910 (1.5\%) in 2005, 5,586 (2.28\%) in 2010, and 3,943 (1.61\%) in 2015. Therefore, there are limitations on directly comparing the number or ratio of empty houses at dong between 2010 and 2015. On this, this study focused on comparing time-series spatial patterns after extracting vacant home clusters for each point of time, using the clustering method. 
centering around the original downtown Seo-gu and Yeongdo-gu. In 2010, 61 dongs (approximately 43\%) were extracted as vacant home clusters after Gangseo-gu was excluded, whereas some districts in Nam-gu, Jung-gu, Sasang-gu, and Dong-gu other than Seo-gu, Yeongdo-gu, and Saha-gu were added. In the case of Gangseo-gu, it may be said that while it was extracted as a district of vacant home clusters in 2005 because it is a district having rural characteristics, its dongs were excluded in 2010 because vacant homes occurred comparatively more at dongs in the original downtown than in Gangseo-gu. On the other hand, in the case of 2015, the cluster expansion to neighbor-

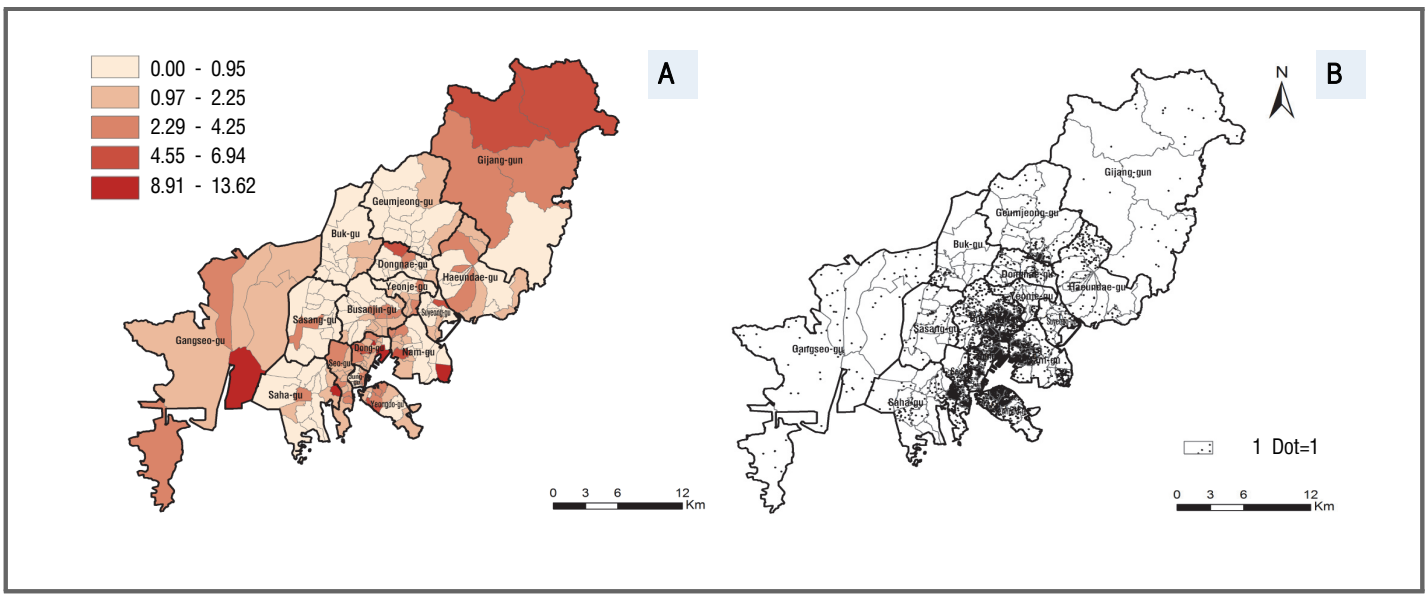

Fig. 2. Distribution map of vacant homes

(A: ratio of vacant homes in 2010; B: number of vacant homes in 2015)

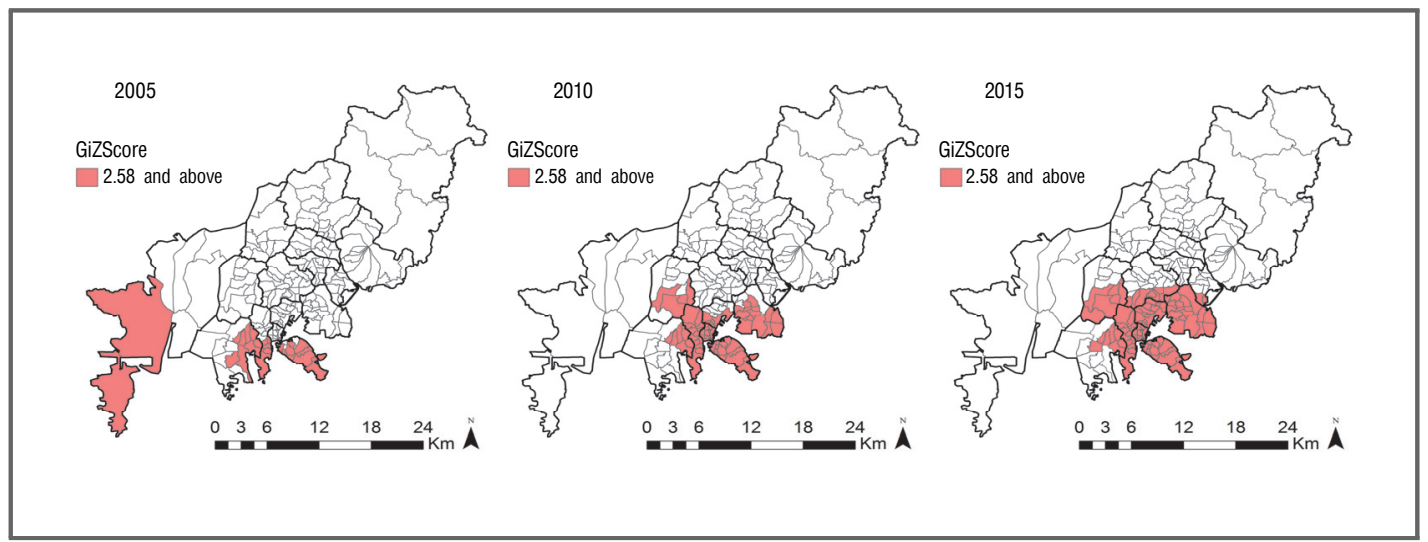

Fig. 3. Extraction of vacant home cluster areas (2005-2015) 
hoods appeared more remarkably, and 86 dongs (approximately 43\%) were extracted as vacant home cluster areas, with even some dongs in Busan-jin-gu and Suyeong-gu being added. Therefore, the number of vacant home cluster areas gradually increased from 23 dongs in 2005 to 61 dongs in 2010 and 86 dongs in 2015.4) Such an expansion of vacant home clusters suggests that vacant homes are continuously increasing to the surrounding areas of the original downtown because though houses are dilapidated and their quality is deteriorated over time, they are neglected without being repaired.
This study overlaid vacant home cluster areas (hot spots) extracted at three time points of 2005, 2010, and 2015 in order to identify whether vacant home cluster areas are fixed in particular space, or are expanded into surrounding areas or is reduced over time. As a result, the following 19 dongs (approximately top $10 \%$ ) in total were extracted as vacant home cluster areas at all the three points of time: the original downtown and surrounding 8 dongs in Yeongdo-gu (Namhang-dong, Dongsam 1-, 2-, and 3-dong, Bongnae 2-dong, Sinseon-dong, Yeongseon 2-dong, and Cheonghak 2-dong), 5 dongs in

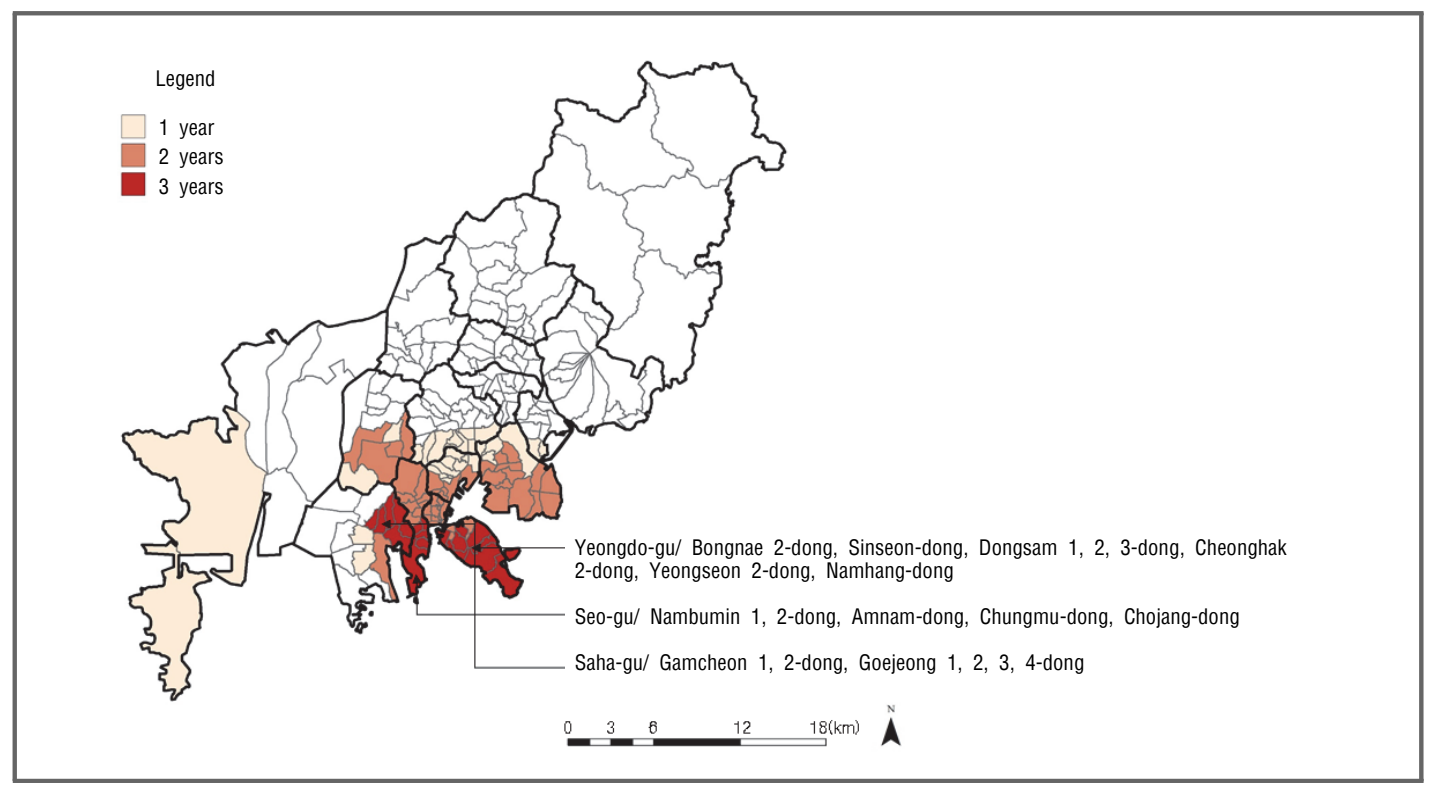

Fig. 4. Spatial fixation of vacant home cluster areas and their expansion to surrounding areas

4) This study excluded three dongs, which actually had a very meager number of vacant homes below 5 , from the extracted cluster areas that showed $G_{i}^{*} \geq 2.58$ influenced by their neighboring districts. 
Seo-gu (Nambumin 1- and 2-dong, Amnamdong, Chojang-dong, and Chungmu-dong), 6 dongs in Saha-gu (Gamcheon 1- and 2-dong, and Goejeong 1-, 2-, 3- and 4-dong). In addition, as for dongs extracted as vacant home cluster areas only in 2010 and 2015, it is found that most of them are surrounding areas of the 19 dongs extracted in common in the three years. That is, they are 13 dongs in Nam-gu (Uam-dong, and Daeyeon 1-, 4-, 5- and 6-dong, Gamman 1- and 2-dong, Yongdang-dong, and Yongho 1-, 2-, 3- and 4-dong), 5 dongs in Dong-gu (Beomil 5-dong, Choryang 1-, 2-, 3- and 6-dong), 4 dongs in Sasang-gu (Gamjeon-dong, Hakjangdong, and Jurye 2- and 3-dong), 8 dongs in Seo-gu (Ami-dong, Bumin-dong, Seodaesin 1-, 3- and 4-dong, and Dongdaesin 1-, 2- and 3-dong), 2 dongs in Yeongdo-gu (Cheonghak 1-dong, and Bongnae 1-dong), and 9 dongs in Jung-gu (Yeongju 1- and 2-dong, Gwangbokdong, Bupyeong-dong, Bosu-dong, Nampodong, Daecheong-dong, Donggwang-dong, and Jungang-dong)(See Fig. 4). These districts, which are equivalent to the original downtown of Busan, are residential areas that were formed during the Korean War, and have become considerably deteriorated; and the number of vacant homes in the districts has increased due to a decrease in population combined with the decline of business districts in the original downtown. In particular, the original downtown has been increasingly fixed as the vacant home cluster area for the past 10 years, and the vacant home clusters are expanding to its surrounding districts.

\section{Analysis of the Characteristics of Vacant Home Cluster Areas}

This study analyzed 19 dongs that were extracted as vacant home cluster areas for the past 10 years, in order to identify how many disadvantaged population who can't improve housing environment with their own efforts or ability reside, how many dilapidated houses exist, how much inferior the neighborhood residential environment is. For analyzing the characteristics of vacant home cluster areas, indicators were selected in consideration of previous studies and theoretical grounds, the representativeness and validity of indicators, availability of data, and correlations between indicators (See Table 1). As variables for indicators showing the socio-demographic vulnerability of residents in the vacant home cluster areas, the ratio of elderly-living-alone, the number of the recipients of national basic living security, and the ratio of undereducated households living at a rental were selected; as variables for indicators of the housing environment of the socially disadvantaged, the ratio of house- 
holds living at dilapidated small detached house, the ratio of households insufficient in water closet, and the ratio of households insufficient in kitchen/bathing facilities were selected; and as variables for indicators of neighborhood residential environment, the ratio of small parcels and the ratio of automobile passage impossible roads were selected.

As for the socio-demographic characteristics of the socially disadvantaged residing in 19 dongs of the vacant home cluster areas, it was found that the elderly-living-alone of $5.5 \%$ and 53.4 recipients of national basic living security (per 1,000) resided at each dong on average, and that $8.0 \%$ of the total households were undereducated households living at a rental (See Table 2). Among households residing in the vacant home cluster areas, the ratio of households living at dilapidated small detached house was up to $13.8 \%$, and the ratio of households using traditional (no toilet) or public toilet also reached $7.4 \%$. The ratio of households using traditional (no hot water) or public kitchen or bathing facilities was also $9.4 \%$ on average. In addition, the ratio of small parcels (below $60 \mathrm{~m}^{2}$ ), which is the representative indicator of neighborhood residential environment, was also $37.9 \%$, and the ratio of automobile passage impossible roads reached $26.8 \%$. Particularly, in the case of Nambumin 1-dong, Seo-gu, the ratio of households insufficient in water closet and the ratio of households insufficient in kitchen or bathing facilities were $15.2 \%$ and $23.3 \%$, respectively. Thus, a considerable number of households residing in the vacant home cluster areas

Table 1 Indicators selected to analyze the characteristics of vacant home cluster areas

\begin{tabular}{|c|c|c|}
\hline \multicolumn{2}{|r|}{ Characteristics indicator } & Formula \\
\hline \multirow{3}{*}{ 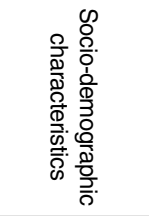 } & Ratio of elderly-living-alone & $\begin{array}{l}\text { Number of the elderly living alone (number of population aged } 65 \text { or over } \\
\text { living alone)/number of resident-registered population } \times 100\end{array}$ \\
\hline & $\begin{array}{l}\text { Number of recipients of national } \\
\text { basic living security per thousand }\end{array}$ & $\begin{array}{l}\text { Number of recipients of national basic living security / number or } \\
\text { resident-registered population } \times 1,000\end{array}$ \\
\hline & $\begin{array}{l}\text { Ratio of undereducated households } \\
\text { living at a rental }\end{array}$ & $\begin{array}{l}\text { Number of households whose head graduated from middle school or } \\
\text { lower and living at a rental / number of total households } \times 100\end{array}$ \\
\hline \multirow{3}{*}{ 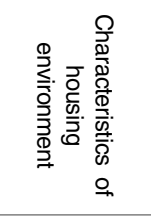 } & $\begin{array}{l}\text { Ratio of households living at } \\
\text { dilapidated small detached house }\end{array}$ & $\begin{array}{l}\text { Number of households living at detached house below } 60 \mathrm{~m}^{2} \text { built before } \\
1980 / \text { number of total households } \times 100\end{array}$ \\
\hline & $\begin{array}{l}\text { Ratio of households insufficient in } \\
\text { water toilet }\end{array}$ & $\begin{array}{l}\text { Number of households using latrine (no toilet) or public toilet / number of } \\
\text { total households } \times 100\end{array}$ \\
\hline & $\begin{array}{l}\text { Ratio of households insufficient in } \\
\text { kitchen/bathing facilities }\end{array}$ & $\begin{array}{l}\text { Number of households using traditional (no hot water) or public kitchen or } \\
\text { bathing facilities / number of total households } \times 100\end{array}$ \\
\hline \multirow{2}{*}{ 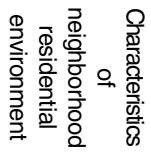 } & Ratio of small parcels below $60 \mathrm{~m}^{2}$ & $\begin{array}{l}\text { Number of small parcels for building site (land category) below } 60 \mathrm{~m}^{2} / \\
\text { number of total building site parcels } \times 100\end{array}$ \\
\hline & $\begin{array}{c}\text { Ratio of automobile passage } \\
\text { impossible roads }\end{array}$ & Length of roads below $4 \mathrm{~m}$ in width/Length of total roads $\times 100$ \\
\hline
\end{tabular}


Table 2 Analysis of the characteristics of vacant home cluster areas

\begin{tabular}{|c|c|c|c|c|c|c|c|c|}
\hline \multirow[b]{2}{*}{$\begin{array}{l}\text { Vacant home } \\
\text { cluster area }\end{array}$} & \multicolumn{3}{|c|}{ Socio-demographic characteristics } & \multicolumn{3}{|c|}{ Characteristics of residential environment } & \multicolumn{2}{|c|}{$\begin{array}{c}\text { Characteristics of } \\
\text { Neighborhood } \\
\text { residential environment }\end{array}$} \\
\hline & $\begin{array}{l}\text { Ratio of the } \\
\text { elderly-living } \\
\text {-alone }\end{array}$ & $\begin{array}{l}\text { Number of } \\
\text { recipients of } \\
\text { national basic } \\
\text { living security }\end{array}$ & $\begin{array}{l}\text { Ratio of } \\
\text { under } \\
\text { educated } \\
\text { households } \\
\text { living at a } \\
\text { rental }\end{array}$ & $\begin{array}{l}\text { Ratio of } \\
\text { households } \\
\text { living at } \\
\text { dilapidated } \\
\text { small } \\
\text { detached } \\
\text { houses }\end{array}$ & $\begin{array}{c}\text { Ratio of } \\
\text { households } \\
\text { insufficient } \\
\text { in water } \\
\text { closet }\end{array}$ & $\begin{array}{l}\text { Ratio of } \\
\text { households } \\
\text { insufficient in } \\
\text { kitchen or } \\
\text { bathing } \\
\text { facilities }\end{array}$ & $\begin{array}{c}\text { Ratio of } \\
\text { small site } \\
\text { parcels }\end{array}$ & $\begin{array}{l}\text { Ratio of } \\
\text { automobile } \\
\text { passage } \\
\text { impossible } \\
\text { roads }\end{array}$ \\
\hline $\begin{array}{l}\text { Mean for Busan } \\
\text { (Except Gijang-gun) }\end{array}$ & 3.7 & 36.4 & 6.5 & 2.0 & 5.3 & 5.8 & 28.5 & 25.5 \\
\hline Mean for 19 dongs & 5.5 & 53.4 & 8.0 & 5.4 & 7.4 & 9.4 & 37.9 & 26.8 \\
\hline $\begin{array}{c}\text { Gamcheon 1-dong, } \\
\text { Saha-gu }\end{array}$ & 2.8 & 31.0 & 5.1 & 1.4 & 3.5 & 5.1 & 10.1 & 20.3 \\
\hline $\begin{array}{c}\text { Gamcheon 2-dong, } \\
\text { Saha-gu }\end{array}$ & 6.7 & 78.7 & 7.4 & 13.8 & 12.6 & 16.1 & 60.3 & 55.0 \\
\hline $\begin{array}{c}\text { Goejeong 1-dong, } \\
\text { Saha-gu }\end{array}$ & 3.2 & 27.9 & 3.1 & 1.2 & 2.7 & 3.2 & 8.6 & 10.6 \\
\hline $\begin{array}{c}\text { Goejeong 2-dong, } \\
\text { Saha-gu }\end{array}$ & 3.5 & 32.9 & 4.0 & 3.5 & 4.3 & 5.3 & 23.6 & 32.9 \\
\hline $\begin{array}{c}\text { Goejeong 3-dong, } \\
\text { Saha-gu }\end{array}$ & 4.2 & 49.8 & 7.4 & 5.1 & 4.8 & 8.2 & 50.1 & 10.8 \\
\hline $\begin{array}{c}\text { Goejeong 4-dong, } \\
\text { Saha-gu }\end{array}$ & 3.1 & 29.0 & 4.1 & 0.8 & 2.3 & 3.4 & 8.0 & 15.9 \\
\hline $\begin{array}{c}\text { Nambumin 1-dong, } \\
\text { Seo-gu }\end{array}$ & 8.0 & 65.1 & 11.4 & 7.3 & 15.2 & 23.3 & 66.4 & 42.2 \\
\hline $\begin{array}{c}\text { Nambumin 2-dong, } \\
\text { Seo-gu }\end{array}$ & 6.2 & 60.4 & 8.4 & 7.2 & 10.4 & 11.2 & 52.7 & 47.5 \\
\hline $\begin{array}{l}\text { Amnam-dong, } \\
\text { Seo-gu }\end{array}$ & 4.2 & 35.2 & 4.3 & 3.1 & 5.8 & 6.4 & 31.4 & 25.4 \\
\hline $\begin{array}{l}\text { Chojang-dong, } \\
\text { Seo-gu }\end{array}$ & 8.5 & 70.8 & 10.9 & 10.1 & 11.5 & 15.7 & 64.9 & 37.3 \\
\hline $\begin{array}{c}\text { Chungmu-dong, } \\
\text { Seo-gu }\end{array}$ & 7.1 & 48.8 & 10.8 & 5.1 & 10.7 & 16.4 & 60.6 & 1.4 \\
\hline $\begin{array}{l}\text { Namhang-dong, } \\
\text { Yeongdo-gu }\end{array}$ & 6.0 & 33.4 & 6.2 & 10.0 & 7.1 & 8.8 & 45.5 & 5.1 \\
\hline $\begin{array}{l}\text { Dongsam 1-dong, } \\
\text { Yeongdo-gu }\end{array}$ & 4.1 & 68.4 & 8.6 & 1.0 & 1.9 & 2.1 & 10.3 & 20.1 \\
\hline $\begin{array}{l}\text { Dongsam 2-dong, } \\
\text { Yeongdo-gu }\end{array}$ & 4.9 & 28.0 & 4.7 & 3.0 & 14.7 & 16.1 & 14.0 & 26.4 \\
\hline $\begin{array}{l}\text { Dongsam 3-dong, } \\
\text { Yeongdo-gu }\end{array}$ & 8.1 & 188.3 & 30.2 & 0.6 & 0.9 & 1.0 & 12.2 & 6.2 \\
\hline $\begin{array}{l}\text { Bongnae 2-dong, } \\
\text { Yeongdo-gu }\end{array}$ & 7.4 & 45.4 & 7.7 & 7.6 & 10.1 & 9.7 & 43.6 & 61.0 \\
\hline $\begin{array}{l}\text { Sinseon-dong, } \\
\text { Yeongdo-gu }\end{array}$ & 7.1 & 58.3 & 9.8 & 10.1 & 12.9 & 13.1 & 60.4 & 46.3 \\
\hline $\begin{array}{c}\text { Yeongseon 2-dong, } \\
\text { Yeongdo-gu }\end{array}$ & 4.7 & 32.3 & 5.2 & 8.1 & 6.5 & 8.6 & 62.7 & 47.3 \\
\hline $\begin{array}{c}\text { Cheonghak 2-dong, } \\
\text { Yeongdo-gu }\end{array}$ & 3.8 & 31.7 & 3.5 & 4.1 & 3.6 & 4.4 & 34.0 & 24.5 \\
\hline
\end{tabular}

90 Journal of Real Estate Analysis Vol.1, No.1 (December, 2015) 
were living in very poor housing environment. In addition, in the case of Bongnae 2-dong, Yeongdo-gu, the ratio of roads below $4 \mathrm{~m}$ in width, which does not allow automobile passage, also reached $61 \%$. Overall, the mean for the 19 dongs of vacant home clusters was found to be very high in every indicator, compared with that for the whole Busan city (except Gijang-gun). Despite the poor level of residential environment in the vacant home cluster areas, the elderly living alone and the poor of lower educational background are living in them because of cheap housing. And the physical residential environment of the neighborhood is also very poor. Given that it is also very likely that the problems of safety, sanitation, and public order will be increasingly serious in these vacant home cluster areas, plans for the management and utilization of vacant home clusters are urgently needed.

\section{The Effects of Vacant Home Clusters on Neighborhood Real Estate Price}

This study first analyzed all the 196 administrative dongs of Busan except Gijanggun to identify the impact of the vacant home cluster areas on the neighborhood land price. For this, data on assessed individual land prices provided by the Korea Appraisal Board and the 2014 Continuous Cadastral Map of Busan were used. Only residential parcels of each dong were extracted to calculate their average land value for three points of time (2005, 2010, and 2015), and then the patterns of the spatial clusters of land value were extracted and compared time-sequentially, using the Hot Spot Analysis of ArcGIS. In particular, the distribution of cold spots, whose land value is relatively low, and the distribution patterns extracted above for the vacant home cluster areas were compared, and the aspect of residential property

Table 3 Correlation between the ratio of vacant homes and real estate price

\begin{tabular}{c|c|c|c}
\hline Division & $\begin{array}{c}\text { Mean price of residential } \\
\text { parcels (2005) }\end{array}$ & $\begin{array}{c}\text { Mean price of residential } \\
\text { parcels (2010) }\end{array}$ & $\begin{array}{c}\text { Mean price of residential } \\
\text { parcels }(2015)\end{array}$ \\
\hline Ratio of vacant homes (2005) & $-0.340^{\star *}$ & $-0.392^{\star *}$ & $-0.418^{\star *}$ \\
\hline Ratio of vacant homes (2010) & $-0.322^{\star *}$ & $-0.334^{*}$ & $-0.362^{\star}$ \\
\hline Ratio of vacant homes (2015) & $-0.404^{\star *}$ & $-0.378^{\star *}$ & $-0.418^{* *}$ \\
\hline
\end{tabular}

** The correlation coefficient is significant at the level 0.01 (two-tailed). 

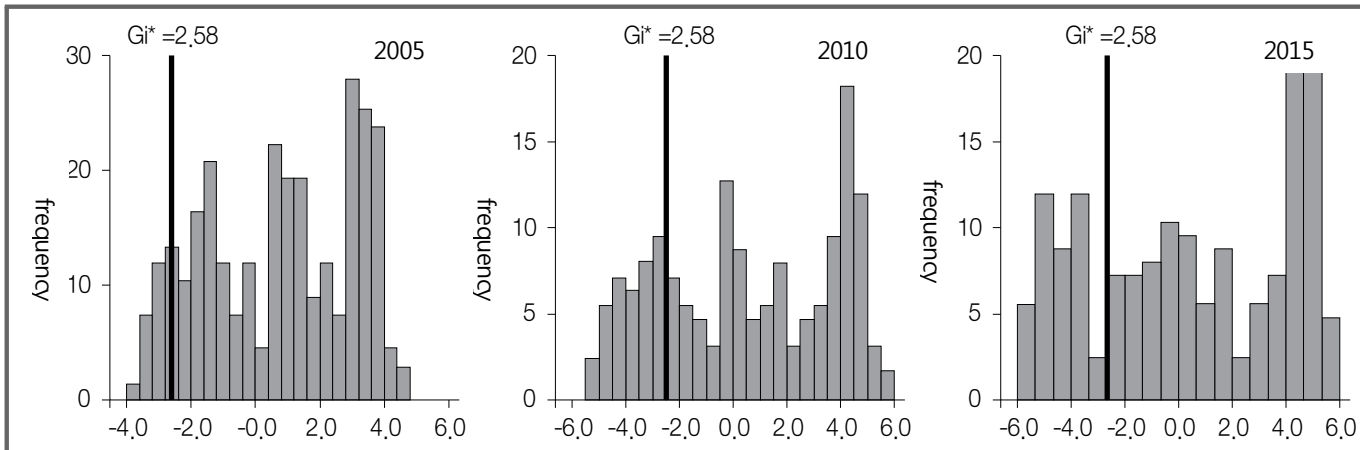

Fig. 5. $G_{i}^{*}$ statistic distributions and distributions with $G_{i}^{*} \leq-2.58$ by dong in Busan

prices in the vacant home cluster areas was visually identified through mapping.

First, the correlation between the vacant home cluster areas and real estate price (the mean land price of residential parcels) was analyzed. As a result, it was found to be -0.340 in $2005,-0.334$ in 2010, and -0.418 in 2015, which shows that there is a clear negative correlation between real estate price and the ratio of vacant homes (See Table 3). This suggests that the land value of residential parcels decreases according as the ratio of vacant homes increases on a dong basis, although given that there are a wide variety of factors that influence land value, the correlation between the two variables was not estimated to be very high.

This study conducted the Hot Spot Analysis of ArcGIS in order to identify the spatial cluster distribution of residential land price for each dong. Here, to identify the cluster of dongs having relatively low land price, dongs of $G_{i}^{*} \leq-2.58$ were extracted (See Fig. 5). As a result, among a total of 196 dongs, 18 dongs (approximately 9\%) were extracted in 2005, 44 dongs (approximately 22\%) in 2010, and 53 dongs (approximately 27\%) in 2015, respectively; and the cluster distribution characteristics of districts having low land price were revealed clearly.

Further, to identify whether the cold spot distribution of land price was being fixed or being expanded to the neighborhood or reduced during a period between 2005 and 2015 , cold spots that appeared in common at the three points of time were overlaid (See Fig. 6). As a result, the original downtown and all the following dongs in the neighborhood of the downtown were extracted as cold spot areas, which had very low land price: three dongs in Yeongdo-gu (Dongsam 1-, 2- and 3-dong), three dongs in Seo-gu (Nambumin 1- and 2-dong, and Ami-dong), 


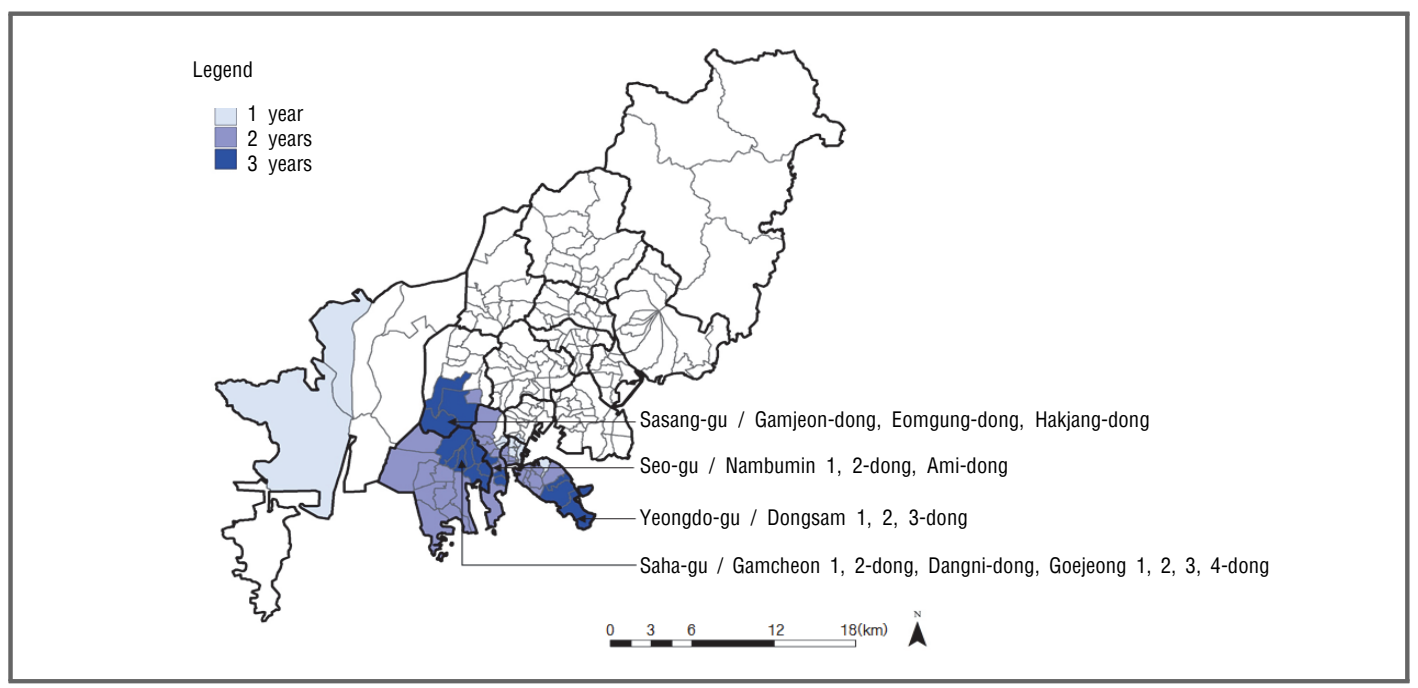

Fig. 6. Spatial fixation of the cold spots of residential parcel price

three dongs in Sasang-gu (Gamjeon-dong, Eomgung-dong, and Hakjang-dong) and seven dongs in Saha-gu (Gamcheon 1- and 2-dong, Dangni-dong, and Goejeong 1-, 2-, 3- and 4-dong). This study mapped and visually compared the correlation between areas having high ratios of vacant homes and real estate price. That is, districts having low land price (cold spots) and areas with high ratios of vacant homes (hot spots) were compared time-sequentially. As shown in Fig. 7, at all the time points of 2005, 2010, and 2015, the distributions of cold spots having relatively low land price and of hot spots having high ratios of vacant homes were fixed, centering around Yeongdo-gu and Seo-gu, which belong to the original downtown, Saha-gu, which is adjacent to Sanbokdoro (hillside road), and some areas of Sasang-gu; and were ex- panded to the Jung-gu area over time. As time passed, while dongs belonging to Gangseo-gu were reduced, the distributions were expanding to Yeongdo-gu, Saha-gu, and Seo-gu. In particular, in 2010, some districts of Jung-gu were added and Gangseogu was excluded completely, and in 2015, Jung-gu was included completely, which shows that the cold spots were expanding to the original downtown.

For more clear identification of the relationship between vacant home cluster areas and districts of low land price, the overlay was carried out to the hot spot areas of vacant home clusters and the cold spot districts of land price according to years (See Fig. 8). As a result, in 2005, 12 dongs in Gangseo-gu, Saha-gu, Yeongdo-gu, and Seo-gu were overlaid; and in 2010, a total of 33 dongs in 


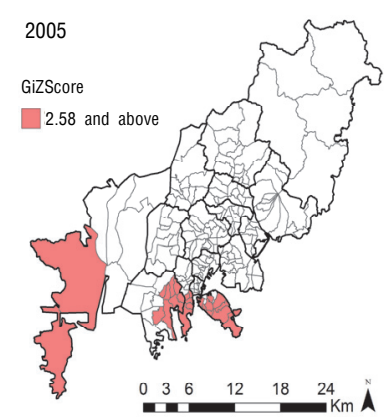

$<$ Vacant home cluster area-hot spot>

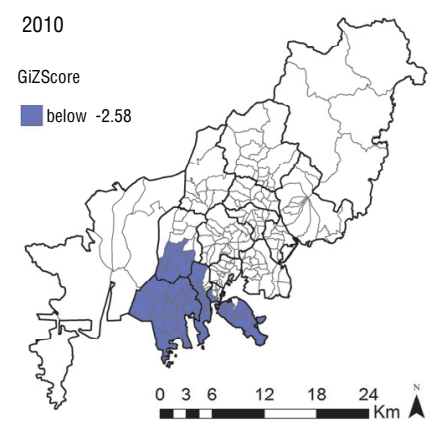

$<$ Mean land price of residential parcels-cold spot>

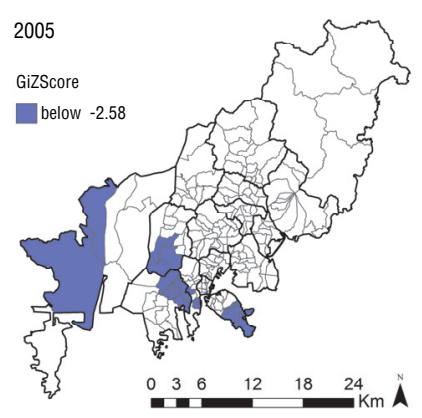

$<$ Mean land price of residential parcels-cold spot>

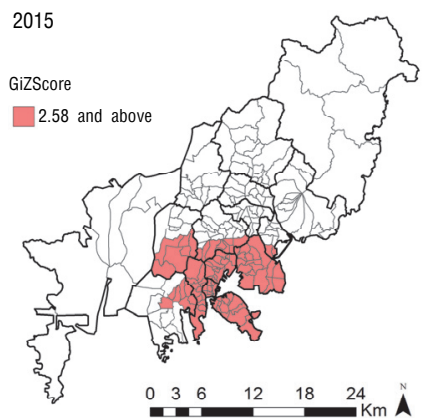

$<$ Vacant home cluster area-hot spot>

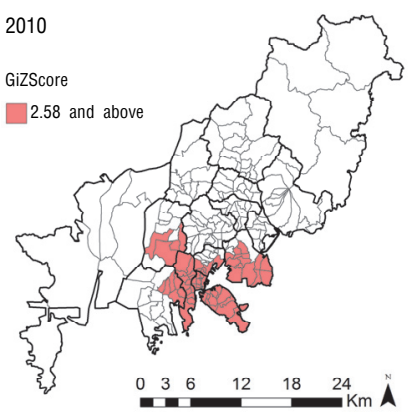

$<$ Vacant home cluster area-hot spot>

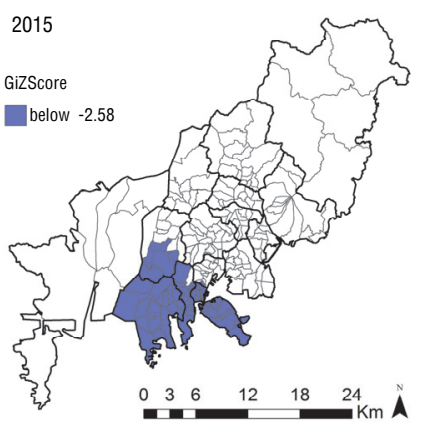

$<$ Mean land price of residential parcels-cold spot>

Fig. 7. Time-series changes in distribution maps for the cold spots of land price and the hot spots of vacant homes

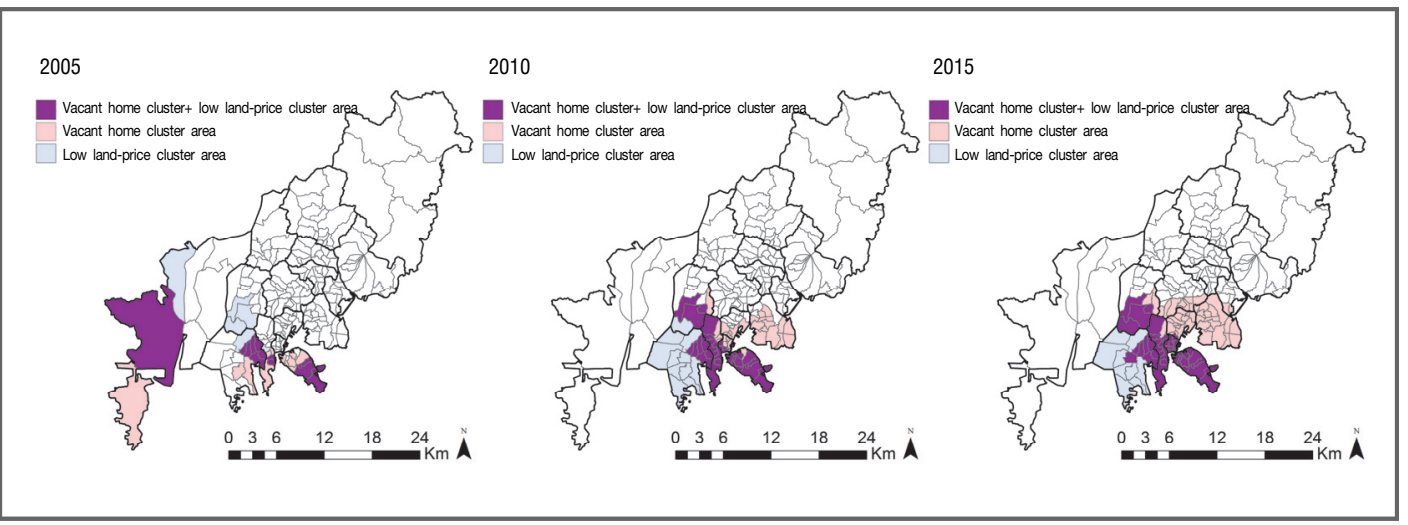

Fig. 8. Time-series changes in overlay patterns between vacant home cluster hot spots and low land-price cluster cold spots

94 Journal of Real Estate Analysis Vol.1, No.1 (December, 2015) 
Saha-gu, Sasang-gu, Yeongdo-gu, Seo-gu, and Jung-gu, respectively; and in 2015, Dong-gu was added to the existing gus, and thus a total of 44 dongs were found to be overlaid areas. Therefore, the spatial patterns of vacant home clusters and low land-price clusters in Busan for the past 10 years show that strong clustering was being fixed at the original downtown and some districts along Sanbokdoro, and was gradually expanding towards surrounding areas at the same time.

\section{Conclusion}

It is recognized that abandoned real estate, particularly the occurrence of vacant homes, induces crimes, injures neighborhood residential environment and the beauty, and has negative effects on the safety and health of community. Meanwhile, problems of dwellings deteriorated due to a decrease in population or economic recession have been addressed through housing redevelopment projects or urban renewal projects carried out pursuant to the Act on the Maintenance and Improvement of Urban Areas and Dwelling Conditions For Residents and the Special Act on the Promotion of Urban Renewal. These projects, however, are mostly dependent on the private sector, and thus residential environment in areas of low feasibility is fur- ther deteriorated and faces slumism. This study aimed to analyze the spatio-temporal patterns of vacant home clusters and the impact of vacant home clusters on neighborhood land price in Busan Metropolitan City, which is experiencing such an accelerated slumism in its existing downtown that top $40 \%$ of the country's deprived dongs are concentrated in the city.

During the period between 2005 and 2015, vacant home clusters in Busan were continuously fixed in the original downtown (Yeongdo-gu, Seo-gu, and Saha-gu), and showed a tendency to gradually expand to their surrounding districts at the same time. As a result of investigating the characteristics of 19 dongs, which were fixed as vacant home cluster areas, it was found that the elderly living alone and the socially disadvantaged such as recipients of national basic living security resided in very deteriorated and inferior housing facilities, and their neighborhood residential environment was also very poor, as evidenced by high ratios of small parcels and high ratios of automobile passage impossible roads.

On the other hand, as a result of calculating the mean price of residential parcels by dong and analyzing the cluster distribution of low land price, it was found that districts of low land price were being fixed around the original downtown (Yeongdo-gu and 
Seo-gu) and some areas along the Sanbokdoro (Sasang-gu and Saha-gu). In particular, it was found that the spatio-temporal patterns of vacant home cluster areas and the cluster patterns of low land-price districts are very similar, which suggests that vacant home clusters have effects on real estate price. In fact, the ratio of vacant homes and the mean price of residential land for each dong show a negative (-) correlation coefficient value between -0.33 and -0.42 , which implies that the higher the ratio of vacant homes, the lower the land price.

In Busan, population has decreased continuously as inner city decline has been accelerated due to the relocation of labor-intensive industry businesses, low fertility \& ageing, and new town development; and consequently vacant homes are increasing rapidly in deteriorated and inferior residential areas. In addition, as districts along Sanbokdoro (hillside road), which are poorly accessible due to the topographical features of Busan, are densely populated by the socially disadvantaged because of low housing price and rents, the occurrence of vacant homes is accelerated and residential areas become slums. However, housing redevelopment projects for the districts are insufficient, and the repair and maintenance of deteriorated housing are not performed, which worsens their residential conditions further. In the case of a district where the socially disadvantaged are densely populated and the ratio of vacant homes is high, residential improvement is actually very difficult. Redevelopment projects, residential environment improvement projects, urban environment improvement projects, and housing redevelopment projects carried out so far were mostly dependent on the private sector, and the role and support of the public sector have been very insufficient. Thus, it is not easy to find a fundamental solution to the problem of vacant home occurrence.

In the case of Busan, however, recognizing the seriousness of the vacant home problem, the Busan government has conducted its own complete enumeration surveys on vacant home status since 2013. In addition, Busan has recently promoted the Happy Village Project other than the existing residential improvement projects or urban environment improvement projects. It may be said that the Happy Village Project is a comprehensive regeneration system for promoting spatial regeneration, social regeneration, and economic regeneration by creating healthy and strong community so that residents in backward villages can solve local problems on their own. But it remains to be seen how much effectively the Happy Village Project will be able to revitalize vacant home cluster areas. What is most crucial 
to the revitalization of vacant home cluster areas is the preparation of institutional mechanism that elicits medium- and long-term plans for utilizing vacant homes, giving full consideration to local conditions. Clearancebased short-term plans on empty houses end up in mere physical action, and have limitations in preventing additional vacant homes or creating local vitality. Therefore, it is most desirable to discover potential resources that can be actually utilized in vacant home cluster areas, and to work out plans together with residents to create facilities needed in the areas. For this, plans for gradual clearance or gradual remodeling should be worked out, and customized methods for urban regeneration appropriate for relevant community should be found. Particularly, as for the problem of how to utilize vacant homes in a relevant district, it is most important to induce the active participation of current residents in the community. If diverse plans and methods like the above stabilize a vacant home cluster area gradually, the area will develop into sustainable community as well as real estate price will rise. Given that Busan is aware of the problem of vacant homes and is groping for methods for the systematic management and utilization of vacant homes, it is deemed that this study may be used as basic information required for establishing policies for the management and utilization of vacant homes in Busan.

\section{References}

Accordino, J. and Johnson, G. T. 2000, Addressing the Vacant and Abandoned Property Problem, Journal of Urban Affairs, 22(3): 301-315.

An, H. J. and Park, H. Y., 2013, Flexible Urban Regeneration: Creative Use of Empty Houses and Vacant Plots - Focused on Temporary Uses and Tactical Urbanism, Journal of Korea Planning Association, 48(6): 347-366. (in Korean)

Branas, C., Cheney, R., MacDonald, J., Tam, V., Jackson, T. and Ten Have, T. 2011, A Difference-in-Differences Analysis of Health, Safety, and Greening Vacant Urban Space, American Journal of Epidemiology, 174(11): 1296-1306.

Burkholdr, S. 2012, The New Ecology of Vacancy: Rethinking Land Use in Shrinking Cities, Sustainability, 4(6): 1154-1172.

Choi, J. P., Lee, Y. J., Ryu, J. W., Byun, N. H. and Moon, G. J., 2010, School Conversion Strategy for Affordable Housing, Journal of the Architectural Institute of Korea, 26(3): 3-11. (in Korean)

Cohen, D., Mason, K., Bedimo, A., Scribner, R., Basolo, V. and Farley, T. 2003, Neighborhood Physical Conditions and Health, American Journal of Public Health, 93(3): 467-471.

Eom, H. T. and Woo, M. J., 2014, The Impacts of Suburban New Town Development on the Decline of Inner Cities, Journal of Korea Planning Association, 49(5): 51-66. (in Korean)

Garvin, E. C., Cannuscio, C. C. and Branas, C. C. 2013, Greening vacant lots to reduce violent crime: a randomised controlled trial, Injury Prevention, 19(3): 198-203. 
Greene, R. P. and Pick, J. B. 2006, Exploring the Urban Community: A GIS approach, Pearson Education, 49-108.

Ha, C. H., Kwak, H. J. and Kim, H. S., 2013, A Study on Utilization and Making Vegetable Garden of Vacant Land and Deserted House in Deteriorated Low-rise Residential Area for Neighbor-hood Regeneration, Journal of the Urban Design Institute of Korea, 14(6): 8193. (in Korean)

Heckert, M. 2013, Access and Equity in Greenspace Provision: A Comparison of Methods to Assess the Impacts of Greening Vacant Land, Transactions in GIS, 17(6): 808-827.

Heckert, M. and Mennis, J. 2012, The Economic Impact of Greening Urban Vacant Land: A Spatial Difference-in-Differences Analysis, Environment and Planning A, 44(12): 30103027.

Hwang, E. K., 2009, An Activation on Increasing of the Elderly Facility through Utilization of Existing Buildings, Journal of the Architectural Institute of Korea, 25(7): 29-36. (in Korean)

Hwang, H. C., Kang, K. and Choi, S. M., 2007, Practical Applications and Location Characteristics of the Abandoned houses and Vacant Lots in Rural Villages, Journal of Korean Society of Rural Planning, 13(1): 19-31. (in Korean)

Kabisch, S., Haase, A. and Haase, D., 2006, Beyond growth - urban development in shrinking cities as a challenge for modeling approaches. In Proceedings of the iEMSs Third Biennial Meeting: Summit on Environmental Modelling and Software, International Environmental Modelling and Software Society, Burlington, USA.

Kang, D. J., 2010, Urban Regeneration Methodology through Reuse of Industrial Heritage Focused on Comparison of Industrial Typology, Journal of the Urban Design Institute of Korea, 11(1): 157-178. (in Korean)

Kaufman, D. A. and Cloutier, N. R., 2006, The impact of small brownfields and greenspaces on residential property values, The Journal of Real Estate Finance and Economics, 33(1): 19-30.

Kim, D. U. and Kim, G. Y., 2013, A Study on the Harmful Effect of the Deserted Building Characteristic, Korea Real Estate Academy Review, 54: 84-97. (in Korean)

Kim, H. G., 2013, Japan's Policy on Empty Houses in Farming and Fishing Villages, Planning and Policy, (2013-11): 94-100. (in Korean)

Kim, H. J. and Yi, S. H., 2011, The Effect of Urban Regeneration Concept Revealed at the Renovation Plans of Under-Used Spaces Focused on the Plans Appeared at the Former Researches, Journal of the Architectural Institute of Korea, 27(6): 103-112. (in Korean)

Kim, Y. J., 2009, A Study on the Meaning and Direction of Idle Space Revitalization, The Journal of Cultural Policy, 21: 185-207. (in Korean)

Kremer, P., Hamstead, Z. A. and Mcphearson, T., 2013, A social-ecological assessment of vacant lots in New York City, Landscape and Urban Planning, 120: 218-233.

Krusky, A. M., Heinze, J. E., Reischl, T. M., Aiyer, S. M., Franzen, S. P. and Zimmerman, M. A., 2015, The effects of produce gardens on neighborhoods: A test of the greening hypothesis in a post-industrial city, Landscape and Urban Planning, 136: 68-75.

Kwak, S. J., 2006, A Study on Contents Development in Revitalizing idle Space, Doctoral dissertation, Kookmin University. (in Korean)

Lee, C. W. and Ji, N. S., 2013, A Study on the Utilization of Empty House for Rural Activation in Korea, Journal of Korean Society of Rural Planning, 19(3): 169-182. (in Korean)

Lee, C. W. and Lee, J. W., 2015, A Study on the Evaluation Criteria for Selective Improvements 
to Empty Homes, Journal of Residential Environment Institute of Korea, 13(2): 67-79. (in Korean)

Lee, C. H., 2011, Reuse of the Abandoned Rail Yards to Restore Green Networks in Seoul, Review of Architecture and Building Science, 55(10): 29-32. (in Korean)

Lee, D. G., Kim, J. H., Lee, J. W. and Ha, J. M., 2005, A Study on a Physical Factor for Empty of House in Multi-Family Housing, Proceeding of Annual Conference of the Architectural Institute of Korea, 25(1): 453-457. (in Korean)

Lee, H. Y., Lee, D. Y. and You, J. S., 2015, Temporal-Spatial Distribution and Neighborhood Environmental Characteristics of Highly Concentrated Districts of the Low-income Elderly in Seoul, Seoul Studies, 16(2): 1-18. (in Korean)

Lee, H. R., Cho, C. H., Ha, B. W., Dong, J. W. and Kim, H. H., 2012, A Study on the Effective Use of Disused School Sites in Urban Area - Focused on an Elementary School in Incheon Metropolitan City, Journal of the Korean Institute of Educational Facilities, 19(4): 39-48. (in Korean)

Lee, J. W., 2013, Exploring a Framework and Measures to Bring Empty Homes Back into Use: in the Case of England, Journal of Korea Planning Association, 48(4): 95-115. (in Korean)

Lee, J. S. and Sung, H. G., 2010, A Preliminary Study on the Revitalization of the Korean Disused Railroads, The Korea Transport Institute. (in Korean)

Lee, J. H. and Shin, J. J., 2014, A Study on the Availability of Vacant Houses as of Community Assets for Regenerating Residential Area, paper for Spring Conference Urban Design Institute of Korea, 380-387. (in Korean)

Lee, W. G., Park, T. S., Park, J. E., Yu, T. H. and Lee, Y, R., 2011, The Study on Urban Regeneration Strategy for the Application of
Regional Assets, Korea Research Institute for Human Settlements. (in Korean)

Lim, Y. K. and Lim, H. S., 2012, Neighborhood Regeneration Policy Proposal on the Revitalization and Reclamation of Vacant Urban Spaces, Architecture \& Urban Research Institute. (in Korean)

Mcphearson, T., Kremer, P. and Hamstead, Z. A., 2013, Mapping ecosystem services in New York City: Applying a social - ecological approach in urban vacant land, Ecosystem Services, 5: 11-26.

N, J. H., 2012, Creating Local Community Activities Core Using Urban Empty Space Focused on Cases of 'Empty Building' Utilization in Tokyo, policy task research report from The Seoul Institute, 1-189. (in Korean)

Nemoto Masatsugu, 2013, Mutual Cooperation of Social Economic Organization and Local Government toward Regional Resource Application: Focused on Renovating Vacant Old Houses in Kamiyama Town, Japan, Journal of The Korean Cadastre Information Association, 15(1): 51-64.

Oh, S. K. and Jeon, Y. E., 2010, The Study on Proposals to Improve the Art \& Cultural Spaces through Unused and Misused Space Focusing on the 'Incheon Art Platform' Art Residency Program, Journal of Culture Industry, 10(3): 133-150. (in Korean)

Oswalt, P.(ed.), 2006, Shrinking Cities: Volume 1 International Research, Ostfildern-Ruit: Hatje Cantz Verlag.

Pagano, M. A. and Bowman, A. O'M., 2000, Vacant land in cities: An Urban Resource, Brookings Institution, Center on Urban and Metropolitan Policy.

Pallagst, K., 2007, Shrinking cities in the United States of America: Three cases, three planning stories, In Conference proceedings of The Future of Shrinking Cities-Problems, Patterns and Strategies of Urban Transformation in a 
Global Context.

Reckien, D. and Martinez-Fernandez, C., 2011, Why do cities shrink?, European Planning Studies, 19(8): 1375-1397.

Robinson, S. L. and Lundholm, J. T., 2012, Ecosystem services provided by urban spontaneous vegetation, Urban Ecosystems, 15(3), 545-557.

Schilling, J., 2002, The revitalization of vacant properties: Where broken windows meet smart growth, Washington DC: International City/ County Management Association.

Schilling, J. and Logan, J., 2008, Greening the Rust Belt: A Green Infrastructure Model for Right Sizing America's Shrinking Cities, Journal of the American Planning Association, 74(4): 451-466.

Suh, Ki. Y. et al., 2011, A Study on the Utilization of Abolished School Buildings and Its Impediment Factors - The Case of Youth Training Center, Journal of the Architectural Institute of Korea, 27(2): 1121. (in Korean)

Wiechmann, T. and Pallagst, K., 2012, Urban Shrinkage in Germany and the USA: A Comparison of Transformation Patterns and Local Strategies, International Journal of Urban and Regional Research, 36(2): 261-280.

Woo, J. H., Kim, J. D. and Jeon, G. P., 2009, A Study on the Creation of Local Cultural Space, Using Idle Facilities, Ministry of Culture, Sports and Tourism. (in Korean)

Yim, J. A., Kim, T. Y. and Park, C. S., 2008, A Study of the Distribution and Characteristic of the Empty Houses and Vacant Floors in Historic District on Cheongju City, Proceeding of Autumn Annual Conference of KHA, (2008-11): 278-283. (in Korean)

Yoon, H. K. and Lee, Y. S., 2008, A Case on Building Reuse of Slaughter-house, Proceedings of the Korean Institute of Interior Design Conference, 10 (1): 63-66. (in Korean)
Yu, K. H. and Lim, Y. K., 2013, Addressing Abandoned and Unfinished Buildings Management: an Institutional Framework, Architecture \& Urban Research Institute. (in Korean)

Received: 19 Oct. 2015

Reviewed (Revised): 1st 12 Nov. 2015

2nd 23 Nov. 2015

Accepted: 27 Nov. 2015

Published online: 31 Dec. 2015 